\title{
Research on the Rhythm Training of the Piano Duet
}

\author{
Rong Fu
}

College of Music, Ningxia University, Yinchuan, Ningxia, 750011, China

Keywords: Piano Duet, Rhythm, Voice Part, Training, Instructional Mode, Instrumental ensemble

\begin{abstract}
In playing the piano, the piano duet is a very special form of playing, it can arouse interest and cooperation consciousness in playing piano, the more important is that it can strengthen the rhythm control, the identification ability of timbre and sound and the ability of cooperation and playing of both sides, in the piano teaching materials, such as the Beyer and Mozart, have a lot of chapter for piano duet to training the learners' rhythm in piano learning. In this paper, the performance of piano duet is discussed in this paper.
\end{abstract}

\section{Introduction}

The piano duet is a playing form of double duo completed on the same piano. It let the player fully enjoy the pleasure of the piano melody and rhythm brought by the cooperation, and good at improving the musicianship of pianist. In the process of the piano duet, the player needs to listen to the other's rhythm, insert voice part to cooperate with in time, make the two voices in the duet melt together organically, so that the image of music becomes more plentiful, enchanting charm, this is a test for the tacit understanding and sense of rhythm harmony between playing partners.

\section{An analysis of key elements in the teaching of Piano Duet}

Objectively speaking, the training of the piano duet can deepen the understanding of the performance of the music, and good command of the rhythmic and melodic of the music, to maximize the emotional response of the players, so before the training of piano duet, the selection and analysis of the following few key elements must be done well.

Analysis on the selection of playing partner. In the teaching of the piano duet, the teacher should choose the music according to the characteristics of the players, but also take the cooperative characteristics of the piano duet music into account, to see whether it is suitable for the tacit cooperation between the playing partners. Generally speaking, in the selection aspect of playing partners for the piano duet, we should choose the soloist that is similar with the player level and the ability in understanding the music, which is good for the two to form an organic whole. If the two collocation power gap is clear, you can share the music in different parts of the program by the form of the main play, to ensure that both sides can grasp the most part of their own grasp, the formation of cooperation in the rhythm of the complementary, so the ultimate goal of the four hand play training or experience cooperation in cooperation with the rhythm of the fun. Again, the choice of partner should also consider playing style, if style of classical music and romantic music style performer when collocation for piano four hands, may in rhythm and pedal force to control aspects of diversity. Because classical music performer of pedal rhythm power control is always strict and conservative, and romantic music player is this tendency toward more freedom and liberty, often can form a strong intensity contrast. Therefore this style of strong contrast in the training and performance of the piano duet of the play is also there, which requires two people through each other to restrict the planning of a specific range of free play to give a new color of the four hand joint. It may require more than two people in control of the rhythm, but once the two sides of the style is complementary and encouraged, the music played by a very strong and dynamic performance of the. All in all, the choice of the piano duet is very important. A different partner means to adapt to different rhythm changes, the same music will be played a different style.

Configuration analysis for performance parts. The question that the main part and the vice part, which part is more difficult for the piano duet has been plagued by controversy in the industry. And in 
fact, for example, the high quality duet pieces of Schubert, Beethoven, Brahms or Mozart's have very high requirements for the technique between the main part and the vice part, especially for the main pair of the skills required to play and the main part of the two part of the balance and so on, so strictly speaking, the the piano duet play with the two part of the performance of the players is the same. In practical teaching, teachers should will be used in the piano piano playing students assigned to track the main rhythm section, let him drive vice accompaniment part playing the harmony listening ability, rhythm of the main and auxiliary balance twice, to play with more coordination, enhance the free-canopy openness of music rhythm thinking.

The importance of the solo practice before the ensemble. In the training of the piano duet music, teachers should arrange the performer of the main and vice part to carry on a solo practice. This approach has two purposes, one is to let the player the first to feel the whole piece of music content and rhythm, before we are familiar with our own voice part, also familiar with the voice part of the collaborator, which is more conducive to the performer in the subsequent cooperation fast with each other achieve unity of understanding. In addition, the performance of the players in the solo exercise process can also be a quick sentence, music levels and rhythm of the music, and so on, the teacher will give the appropriate answer, to rule out the existence of the ensemble before the existence of various doubts.

The second is to fully understand the whole rhythm of another voice. Four hand joint play requires that the players play a keen sense of the rhythm of each other. Although playing in solo practice content of practice is playing a single voice, but players actually have a chance in solo practice experience ensemble in the second stereo voice rhythm, which is also known as four hand piano ensemble of the overall rhythm feeling. So this is what the player must be familiar with and analyze in the solo exercise process in advance, to help to improve the tacit agreement with the collaborator ${ }^{[1]}$.

\section{The training techniques of rhythm for the piano duet}

After the above analysis of the rhythm training of the piano duet to play the key elements of the analysis, we should begin to explore the rhythm of the type of music training skills. The four hands of the piano with its unique advantages, such as playing in other musical instruments is difficult to do, so the piano four hands can be open to the players of the visual field, as well as the appreciation of the aesthetic ability of music art. During the training process, the training objective of the musical rhythm of the players can be achieved by the proper and reasonable ensemble skills, the use of the pedal and the performance of the musical thinking.

On rhythm training techniques of the ensemble. The ensemble of piano duet can be subdivided into two parts, the beginning and the end of the song, which should be based on the rhythm of the rhythm.

The processing at the beginning of the music

The beginning sound of the ensemble of piano duet and the ensemble of principal deputy. When four hand piano repertoire alliteration and began to play and collaborators playing should breathe to suggest side played, two people and put your hands on the keys, to playing the main micro carrying wrist as a signal and second moment touch keys began to play. In this process, the main play of the wrist lift rate also represents the speed and rhythm of the music to start, this action is simple, but also requires the two to achieve a tacit understanding after repeated practice.

And for some of the main and auxiliary voice after legato four hand piano repertoire and playing also to vice played a clear sign that is similar to a), but the side played to more through have begun playing the main voice to judge himself into the music of the time. For example, if playing the main voice of the play is 6 / 8 pats, then vice played the voice should quickly grasp the rhythm feeling, in 6 hours after the shoot naturally follow solo voices into the melody. Just when playing the main part of the piano sonata vice should be hand over the keys, wait for a natural start playing voice playing side coordination.

The processing at the end of the music

At the end of the music, if there are no pedal to portable early up, to avoid echoes caused due to raise the pedal, the influence of music at the end of the perfect. And some music in the end is the 
lingering with extension of, of both the then ensembles were to step away from the timing of the pedal to to the tweedle sound effect with each other mainly used to judge of music at the end of the treatment. In general, four hand piano ensemble practice early does not recommend ensemble who step on the pedal, because of playing both sides may also did not familiar with each other between the content of voices, if this chaotic pedal, it is easy to cause chaos in the musical part song, due to the inability to listen to clear each other's music performance and cause grasp the rhythm of out of control. Therefore the Lord played side played should be familiar with each other voices, music and melodic rhythm changes after, and then choose pedal, which is based on the angle of rhythm control to improve the ability to use the pedal.

\section{A practical training method of rhythm in the piano duet.}

Rhythm refining training based on time-counting

Time-counting is the piano practice method many music teachers will teach students, as the required practice content for the piano learners, the requirement for time-counting in the piano duet is more refined and precise. It requires the performer reasonable resolution for the whole rhythm of the music under the premise of keeping playing accurately.

In the third movement of Mozart's " Piano Sonata in D Major for Piano Duet" , the time signature of the works is in 2 / 4 signature, and counting the signature should be $1,2,1,2 \ldots \ldots$, but the due to the triplet, eighth notes and with ornaments of dotted eighth notes, so must according to their rhythm of refinement, strengthen the rhythm exercises. As shown in Figure 1.

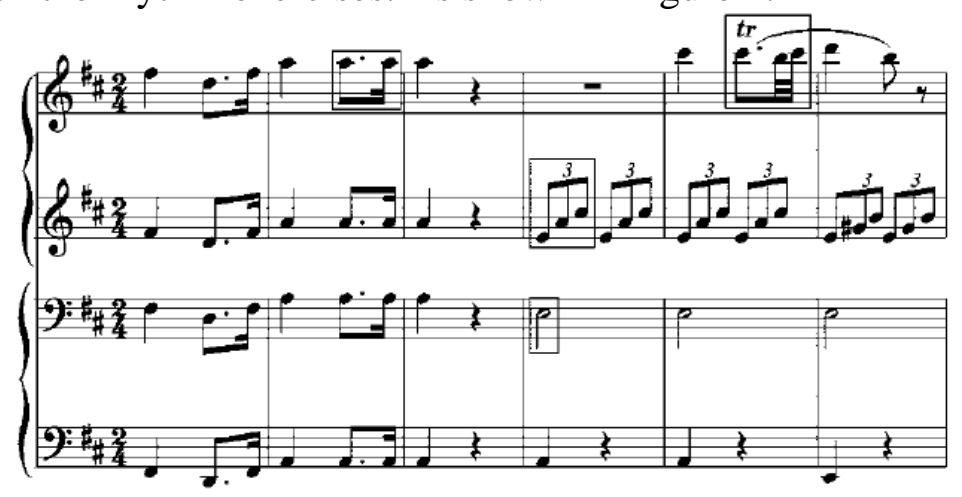

Fig. 1. In the third movement of " Piano Sonata in D Major for Piano Duet"

In this section of music, the refinement method of the main part and the sub - outs should be as follows: First, the refinement method like while the refinement method like

It also can be seen from these small examples that the training process for the rhythm refining in the piano duet is the accurate processing for the main part beat. The stability of the rhythm brings a decisive impact on the controlling of the whole track, and is a symbol of success of controlling the rhythm.

\section{Individual and preoperative instruction of difficult rhythm}

There are difficult phrases of high and low voice existing in the piano duet works, and it will also appear alternately, so coping strategy should be made to adjust to the difficult rhythm of the music in each separate training and cooperation training between the partners. First of all, two collaborators to start training alone, their own voice to the rhythm of skilled practice and two people do alliteration department with the training. In conjunction with training, bass player in the face of loud rhythm difficult phrase, should try to slow playing speed, patience to cater to the loud rhythm. On the other hand, so that the sound of the loud, so that it can be the first to lay a good foundation for the entire music. For example, in Schubert's piano duet works "Fantasia in F Minor", with span of high and low voice, although large, but players do high and low voices together, with three legato formed a great difficulty for the octave, and build a more muddy thick bass effect for the entire movement. 


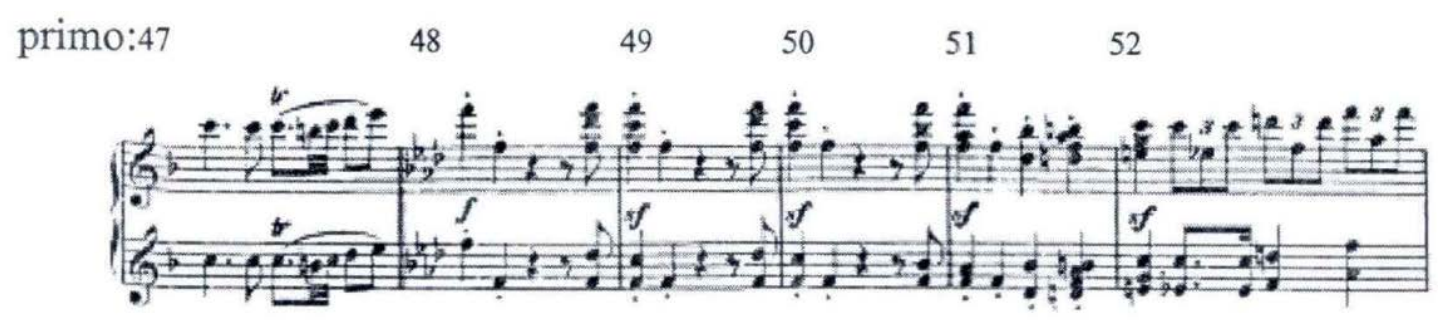

Fig. 2. The movement of "Fantasia in F Minor"

As shown in Figure 2, "Fantasia in F Minor" uses tercet fragment by the loud 6 octave triplets in this movement, which corresponding to high and low two voices of the melody is ensemble. Two members of the four hands playing in the same direction, the whispered to the Department of the triplet rhythm increased rapidly, and loud in each triplet first appeared as a melody, also whispered to the Department also uses the a octave repeated with a bass. If the ensemble who can in the triplet performing slightly out of the first tone and with a single stroke after two tone, can form a movement of the whole line smooth coherent and no respiratory standstill perfect performance, give a person a music overall forward constantly promote feeling ${ }^{[2]}$.

Training of rhythm with variable speed

If you think you can have a good command of the track, you will be able to master it. Strictly speaking, in the initial grasp of the rhythm and the rhythm of the track and can be smooth after the rhythm of the music should be carried out on the rhythm of the rhythm of the transmission, many players in the rhythm of the practice found that the problem of implicit memory. For example, some of the rhythm of the difficulty of the paragraph error, or two people with the consistency of the play is not stable, etc.. The practice is very simple, it requires the performer to be able to finish the track in the rhythm of the rhythm, and the rhythm of the rhythm of the rhythm of the rhythm of the process, which includes some of the rhythm of the rhythm of the music and the rhythm of the rhythm of the rhythm of the error caused by the rhythm and the rhythm of the. The next second stage is slow, the main purpose of slow exercise is to correct the problems in the fast playing. The normal rhythm in slow practice for a period of time, the rhythm with stability and a thorough understanding of the difficulties with skill, you can in the ensemble who mutually acceptable repertoire. This "three step" method is more scientific and reasonable, it takes into account the rhythm between the players to control, breathing and the music to feel the control, the purpose is to require that the ensemble can form a complete understanding of the rhythm in different rates, so as to maximize the reduction of the low-level error which may occur when the formal performance begins ${ }^{[3]}$.

\section{Conclusion}

The sense of timbre, depth, balance and music thought brought by piano duet for the composition are rich, and it is all the controlled and explained by the correct reasonable rhythm. So, when carry on music ensemble for piano duet, the scientific training of the rhythm must be strengthened and to listen carefully to each other, seek a meeting point of prosody rhythm, let the music melody and bitonal tone perfect integration being a whole, to show the rich connotation the piano duet pieces want to express.

\section{References}

[1] Chen Jing.On the importance of the piano duet in Piano Teaching.Northeast Normal University, 2007.17-21.

[2] Chen Ye.Contrast of the two performing versions of Schubert Fantasia in F Minor for piano duet.Fujian Normal University, 2013.41-46.

[3] Lan Fang.A practical method for the training of the piano duet.China Music Education, 2012,(7):22-23. 